\title{
TWENTY YEARS OF THE CENTRE FOR PHYSICAL ANTHROPOLOGY
}

\author{
Helje KaARma
}

Centre for Physical Anthropology, University of Tartu, Tartu, Estonia

The article provides an overview of the activities of the Centre for Physical Anthropology at the University of Tartu from its foundation in 1993 to the present.

Anthropological research in Estonia has seen nearly two hundred years of complicated and discontinuous development. The long-time traditions and vitality of anthropology were confirmed by the fact that after the Republic of Estonia gained its independence in 1991, the Centre for Physical Anthropology, founded on 19 July 1993, was the first independent research centre established in the course of the reform of the University of Tartu. The Centre began operating at the Institute of Anatomy at the University. Its aim was to conduct and coordinate anthropological research at the University of Tartu and in the whole of Estonia. Additionally, the Estonian Anthropometric Register was founded at the Ministry of Social Affairs in 1995. The statutes of the Register fixed its aims as follows:

1. Collection and storage of historical data and data gathered during various scientific studies on Estonians' body build and related data on people's health and making them technically accessible.

2. Collection and storage of anthropometric data on various groups of population according to a uniform scheme.

3. Carrying out anthropometric measurements commissioned by the state or its institutions and storage of these data.

4. Analysis of data stored in the register for drawing theoretical conclusions and giving practical recommendations for their application. 
During the years of its existence, the Centre for Physical Anthropology has united the anthropologists from several departments of the University of Tartu, from the Institute of History at Tallinn University, and from the National Institute for Health Development.

The Centre has trained a number of new experts. Under the supervision of Helje Kaarma, two doctoral theses (G. Veldre and R. Stamm), one candidate's thesis (S. Liivrand) and eight master's theses (G. Veldre, J. Raud-Varjas, M. Salundi, M. Lintsi, K. Loolaid, K. Ohvril, K. Lehto and K. Oun) have been defended.

The consultant of the Centre on statistics has been Professor Emeritus EneMargit Tiit, and practical statistical analysis of data has been carried out by the recently departed Master of Statistics Säde Koskel.

The Estonian school of anthropology was founded by Juhan Aul with his comprehensive study of physical development of Estonian men, women and schoolchildren. In 1938 Juhan Aul proposed founding an anthropological research institute at the Estonian Academy of Sciences. Although due to the war and the occupation the institute was not founded, J. Aul's extensive studies (approximately 50,000 subjects) provided a comprehensive overview of the anthropology of Estonian men, women and schoolchildren. He wrote the voluminous books Eestlaste antropoloogia - Anthropologia Estonica (Anthropology of Estonians, 1964) [1], Eesti kooliõpilaste füüsilise arengu hindetabelid (Tables of Physical Development of Estonian Schoolchildren, 1974) [2] and Eesti kooliõpilaste antropoloogia (Anthropology of Estonian Schoolchildren, 1982) [3]. For better supervision of anthropological research, J. Aul founded in 1939 the Anthropology Section of the Estonian Naturalists' Society.

When the Centre for Physical Anthropology was founded, it set itself the aim to create a classification that would enable physicians and biologists to systematise all the anthropometric variables. For multivariate statistical analysis of the body as a whole, the following cohorts were studied: 1) schoolgirls aged $7-18$ years, $n=1500 ; 2$ ) young men - conscripts aged $17-18$ years, $n=1500) ; 3$ ) schoolgirls aged 15-18 years from all the secondary schools of Tartu, $n=1114$; 4) male students of final years of secondary schools of Tartu aged 17-18 years, $\mathrm{n}=253$; female students of different faculties of the University of Tartu, aged $18-22$ years, $\mathrm{n}=670 ; 6)$ pregnant women patients of Tartu Antenatal Clinic, $\mathrm{n}=900$. 
All these samples were studied anthropometrically and with equal thoroughness. Thirty-six body measurements and 12 skinfolds have been taken; 64 indices and body composition characteristics have been calculated.

Multivariate statistical analysis began with the sample of 670 female students aged 18-22 years [5]. Anthropometric variables were found to form a set of statistically significant relationships where the leading characteristics were height and weight. This led to the idea that the basis for classification of individual anthropometric characteristics might be height and weight. Whether this could be true was tested by studying the behaviour of individual characteristics and indices in height-weight classes. For the purposes of analysis, the sample was divided into $5 \times 5=25$ standard deviation (SD) classes. The whole material was divided into five SD classes. In all height classes, the gradual increase in weight brought about a gradual increase in breadth and depth measurements, circumferences and skinfolds. On the contrary, based on five different weight classes, we observed what happens when height increases. We noticed a gradual increase in length measurements and a gradual decrease in breadth and depth measurements and circumferences.

These regularities concerned the general sample. Now, it was necessary to find whether the classically different somatotypes - pycnics and leptosomes would behave differently. For the comparison between themselves and with the general sample we consulted with Prof. Juhan Aul. He advised us to single out, during somatoscopic measuring, only the purest representatives of the type, and to measure them in the same way as the subjects of the general sample. Thereafter, we had to compare the types between themselves and the general sample. In the whole sample, we found 32 pure pycnics and 39 pure leptosomes. It turned out that the mean individual characteristics and proportions of the group resembled the changes in the general sample when weight gradually increases in the same height class. The trends in the group of leptosomes resembled the changes in the general sample when in the same weight class height gradually increases.

So, finally we were able to solve the problem of the structure of anthropometric measurements of the body as a whole. The body as a whole does not consist of groups of different structures but the whole anthropometric structure of the body in both the general sample and somatotypes is based on the same principles - on relations between height and weight. 
It became evident that different classifications of height and weight can be recommended for physicians and anthropologists for systematisation of their research material. For example, $3 \times 3$ or $5 \times 5$ classes or some other variants can be used.

There was a need to develop a height-weight classification with a relatively small number of classes where the classes could be differentiated from one another as essentially different somatotypes. There we relied, on the one hand, on the view of the German anthropologist Knussmann [8] that in the process of classification it should be possible to differentiate clearly between magnitude classes of height and weight. The other view was that of Kretschmer [10] that pure constitutional types existing in the population should be distinguishable.

We based our classification on $3 \times 3=9$ SD classes of height and weight where we first formed three classes of concordant height and weight: (1) the small class - small height and small weight; (2) the medium class - medium height and medium weight; (3) the large class - big height and big weight. The remaining six classes were united into two classes of disconcordant height and weight. Thus, the fourth class is the class of pycnomorphs with relatively small height and big weight, and the fifth is the class of leptomorphs with relatively big height and small weight (see Fig. 1).

\begin{tabular}{|c|c|c|c|c|}
\hline \multicolumn{5}{|c|}{ Weight classes } \\
\hline \multirow{4}{*}{$\begin{array}{l}\text { Height } \\
\text { classes }\end{array}$} & & Light & Medium & Heavy \\
\hline & Short & Small & & \multirow{2}{*}{$\begin{array}{l}\text { Pycno- } \\
\text { morphic }\end{array}$} \\
\hline & Medium & Lepto- & Medium & \\
\hline & Tall & morphic & & Large \\
\hline
\end{tabular}

Figure 1. Body build classes

Next, we applied our new five-class system to analyse all the material collected earlier. In all samples we found the same characteristic system. Classes 1, 2 and 3 showed a gradual significant increase in all the measurements. The class of pycnomorphs differed significantly from the class of leptomorphs.

The body build regularities found by us in our five-class classification allowed C. Raschka in his book Sportanthropologie [13] to call our classification a new Estonian system of constitutional typology.

Thus, we can recommend the above-mentioned classification for use in medicine and health promotion where a number of different aspects could be simultaneously analysed in the same class. 
The regularities in the sample of conscripts aged 17-18 years studied by M. Lintsi [11] allow us to recommend this system for studying the health of conscripts.

Anthropometric research of schoolgirls aged 7-18 years confirmed the existence of the same body structure in all age groups [6]. G. Veldre's research results were particularly valuable as they confirmed the existence of the same regularities in the body structure of pubertal girls and boys $[14,15]$. These results could be used by school physicians for assessment of school students' health and physical development.

Research of nutrition of female students aged 17-23 years confirmed the existence of essential somatotypic peculiarities [12].

In addition to the aforementioned, the Centre for Physical Anthropology has participated in establishing the national norms of height, weight and body mass index of Estonian children aged 2-18 years $(n=20,000)$ [4]. The Centre participated in compiling the most recent height-weight norms of Estonian schoolchildren, which date from 2006-2009 [9].

A major area of research in recent times has also been establishing the height and weight norms of adult Estonian men and women (aged 20-70 years) and demonstrating the possibilities of somatotyping these data by means of a height-weight classification [7].

The Centre has regularly published its collection of research papers, Yearbook of the Estonian Anthropometric Register (1998-2002), and from 1992 to the present, the annual international collection Papers on Anthropology, which has by this year reached its $22^{\text {nd }}$ issue.

The Centre thanks its supporter and financier Prof. Andres Arend from the Institute of Anatomy, Emeritus Professor Ene-Margit Tiit, language editors Ilmar Anvelt and Mall Tamm, Tartu University Press, and our colleagues - Leiu Heapost, Liidia Saluste, Gudrun Veldre, Mart Lintsi, Jaan Kasmel, Jana Peterson, Kersti Loolaid, Liidia Kiisk and Maie Toomsalu for their cooperation.

\section{REFERENCES}

1. Aul J. M. (1964). Anthropology of Estonians. Transactions of the University of Tartu. Issue 158. Tartu (in Russian).

2. Aul J. (1974). Tables for Assessment of Physical Development of Estonian School Students. Tallinn: Valgus (in Estonian). 
3. Aul J. (1982). Anthropology of Estonian School Students. Tallinn: Valgus (in Estonian).

4. Grünberg H., Adojaan B., Thetloff M. (1998). Kasvamine ja kasvuhäired. Metoodiline juhend laste füüsilise arengu hindamiseks. (Growth and growth disorders. Methodological instructions for assessing children's physical development) (in Estonian).

5. Kaarma H. (1995). Complex statistical characterization of women's body measurements. Anthropologischer Anzeiger 53 (3), 239-244.

6. Kaarma H., Stamm R., Kasmel J., Koskel S. (2005). Body build classification for ordinary schoolgirls (aged 7-18 years) and volleyball girls (aged 13-16 years). Anthropologischer Anzeiger 63 (1), 77-92.

7. Kaarma H., Saluste L., Lintsi M., Kasmel J., Veldre G., Tiit E.-M., Koskel S., Arend A. (2008). Height and weight norms for adult Estonian men and women (aged 20-70 years) and ways of somatotyping using a height-weight classification. Papers on Anthropology XVII, 113-130.

8. Knussmann R. (1961). Makrosomie - Mikrosomie als Körperbautypologie. Variationsreihe II. Ordnung. Homo 12, 1-16.

9. Koskel S., Tiit E.-M., Kaarma H. (2010). Changes in Estonian school students' height and weight in the last ten years. Papers on Anthropology XIX, 211-223.

10. Kretschmer E. (1961). Körperbau und Charakter. Berlin - Göttingen - Heidelberg (1. Aufl. 1921).

11. Lintsi M., Kaarma H. (2003). Five-class height-weight model for systematization of seventeen-year-old recruits' anthropometric data. Anthropologischer Anzeiger 61 (4), 435-443.

12. Peterson J., Kaarma H., Koskel S. (2007). Using height-weight classification for analysis of food energy and main nutrient content in 24-hour menus of 17-23-year-old Estonian female students. Anthropologischer Anzeiger 65 (1), 51-53.

13. Raschka C. (2006). Sportanthropologie. Köln: Sportverlag Strauss, 219-220.

14. Veldre G., Stamm R., Koskel S. (2002). A possibility of systematization of anthropological data of girls aged 12-15. Anthropologischer Anzeiger 60 (4), 369-382.

15. Veldre G., Jürimäe T. (2004). Anthropometric parameters and sexual maturation in 12 to 15-year-old Estonian boys. Anthropologischer Anzeiger 62 (2), 209-215.

\section{Address for correspondence:}

Helje Kaarma Dr. Sc., Dr. med.

Centre for Physical Anthropology

Institute of Anatomy

Faculty of Medicine

University of Tartu

E-mail: antrop@ut.ee 